\title{
GESTIÓN DE DESTINOS E INFORMACIÓN CONFIABLE
}

\section{DESTINATION MANAGEMENT AND RELIABLE INFORMATION}

\author{
Katia Beatriz Herz Castro \\ Universidad de San Martín de Porres, Perú
}

\section{RESUMEN}

La importancia de la adecuada gestión del destino turístico es un aspecto que muchas veces es tomado a la ligera en cuanto a la información que se utiliza para definirlo. La falta de información, la información sesgada o equívoca de algunos conceptos, datos estadísticos no actualizados e incluso la débil información primaria obtenida, han llevado al desarrollo de proyectos o iniciativas que no han tenido buenos resultados. Qué información utilizar, qué puntos son claves para definir un destino, qué actividades realizar para este fin y con qué actores se debe de interactuar para lograr resultados óptimos, son siempre aspectos que han generado debate o simplemente no se han tomado en cuenta, llegando muchas veces a «imitar» iniciativas que, habiendo podido ser exitosas en algunos lados, no siempre son acordes a nuestra realidad. Siendo el Perú un país con tanto potencial turístico y muchas zonas aún por explotar, este es un tema primordial para el desarrollo del turismo como una alternativa para el desarrollo local.

Palabras clave: Gestión de destino, destino turístico, gestión turística, modelo de gestión.

\begin{abstract}
The importance of proper management of tourist destinations is an aspect that is often taken lightly as the information used to define it. The lack of information, biased or misleading information of some concepts, not updated statistics and even a weak primary information obtained, led to the development of projects or initiatives that have not had good results. What information should use, which points are key to define a destination, what activities performed for this purpose and how actors must interact to achieve optimal results, are always aspects that have generated discussion or just have not been taken into account, reaching, often, to «imitate» initiatives which, having been successful in some places, are not always according to our reality. Being Peru a country with so much potential for tourism and many untapped areas, this is an essential issue for the development of tourism as an alternative for local development.
\end{abstract}

Keywords: Destination management, tourist destination, tourism management, management model 


\section{Introducción}

La gestión del destino turístico es uno de los temas que ha concertado mayor debate teórico en la actividad turística. La academia no es ajena a este productivo debate. Sin embargo, poco se ha dicho de la importancia de la información para el éxito de un modelo de gestión concreto en un destino específico. El presente artículo apunta a proponer este ángulo de análisis, bajo la hipótesis de que solo con base informativa confiable será posible desarrollar un modelo de gestión viable en los diferentes destinos turísticos que reúnan las condiciones adecuadas.

Por supuesto, no solo se trata de información pero la información es condición sine qua non de la gestión. Es lo que intentaremos demostrar ahora.

\section{Objetivo}

El propósito del presente artículo es establecer la importancia de la información pertinente para una eficiente gestión de destinos turísticos.

\section{El destino turístico como referencia}

Uno de los temas más discutidos en la actualidad es el concepto de destino turístico, diversos autores han distinguido componentes diferentes para la definición del destino. No es nuestra intención introducirnos en tal debate. Por ello, tomaremos como base la definición estándar de la Organización Mundial de Turismo (OMT), a saber:

Un destino turístico es un espacio físico en el que un visitante puede pernoctar al menos una noche. Este incluye productos turísticos considerando servicios de soporte, atractivos y recursos turísticos que son accesibles en el lapso de un viaje de ida y vuelta de un día. El destino tiene límites físicos y administrativos que definen su gestión, así como una imagen y percepciones que definen su competitividad en el mercado. Los destinos turísticos involucran a diversos actores incluyendo generalmente a la comunidad local, y pueden ser la base para formar una red que forme destinos más grandes. (OMT, 2002)

Esta definición, sin alterar su contenido, ha adquirido nuevo formato resumen y actualmente se formula como el ...

Espacio donde el turista pasa como mínimo una noche que incluye el consumo de productos turísticos tales como servicios básicos y suplementarios. El destino tiene fronteras físicas y administrativas, con una gestión propia definida, que en su imagen y perceptibilidad define su competitividad en el mercado. (OMT, 2011)

Para Barrado (2004) esta definición incluye elementos de espacio (recursos turísticos e infraestructura de soporte), de administración (normatividad y políticas públicas) y de producción (oferta de productos turísticos 
y de servicios complementarios así como flujos de inversión), pero además, distintas interrelaciones con diversos efectos económicos, territoriales, sociales y ambientales.

Entendido así, el destino turístico no solo es la unidad de gestión turística por excelencia, sino también la más importante unidad de análisis turístico. Es decir, al constituirse en el escenario global de la visita, el destino requiere ciertamente administración eficaz pero no podrá haber adecuada administración sin análisis pertinente previo y no existe análisis apropiado sin información confiable.

Por otro lado, la lógica del destino como unidad de planificación es consustancial al desarrollo sostenible del turismo. La gestión del destino debe ser planificada. Desde 1985 -gracias a Boullón (2006) entre otrosestá claro que el desarrollo espontáneo del turismo conduce inevitablemente a la depredación del espacio turístico. De modo que cualquier destino turístico que pretenda sostenibilidad -y competitividad- requiere de algún nivel de planificación.

Un destino sostenible y competitivo necesita sustentarse en un conjunto de elementos de base indispensables, de los cuales, los tres siguientes son los más importantes:

a. Masa crítica de atractivos turísticos, que permita construir una cartera de productos consistente. Esto implica no solo factores cuantitativos sino sobre todo cualitativos, particularmente el período de visita requerido, para determinar su efectivo potencial de convocatoria.

b. Mercados emisores identificables, que permitan flujos suficientes de visita. Aquí lo determinante es medir la demanda potencial a fin de establecer la rentabilidad económica de la operación turística en el territorio.

c. Dinámica institucional pública y privada positiva, que permita desarrollar una gestión adecuada para el encuentro entre los potenciales de oferta y demanda identificados. En este punto lo fundamental es la capacidad de los actores de construir una gerencia consensuada.

Determinados los pilares que deben soportar la planificación y gestión del destino, no debe quedar duda de la información igualmente imprescindible que dicha planificación y gestión requieren. Es lo que veremos a continuación.

\section{Inventario de atractivos turísticos}

Lo primero es disponer de un inventario jerarquizado, priorizado y organizado de atractivos turísticos del destino. A este respecto debe precisarse que no se trata de disponer de una lista extensiva de atractivos (que son los recursos turísticos que cuentan al menos con flujos iniciales de visita), se trata de establecer una relación de aquellos atractivos con elevada jerarquía, capaces de atraer flujos significativos de visitantes si es que se articulan con criterio y se complementan con servicios correspondientes.

Para el efecto, es necesario recordar que existe una jerarquización de elevada utilidad formulada en términos muy sencillos por los técnicos del Centro de Investigación y Capacitación Turística (CICATUR) de la Organización de Estados Americanos (OEA): 
- Jerarquía 3, que corresponde a aquel atractivo excepcional y de gran significación para el mercado turístico que es capaz, por sí solo, de atraer flujos turísticos internacionales.

- Jerarquía 2, que corresponde a aquellos atractivos de alta importancia que, asociados con otros del mismo valor son capaces de provocar flujos turísticos internacionales.

- Jerarquía 1, que corresponde a aquellos atractivos que, individualmente o asociados, pueden provocar importantes flujos turísticos internos, incluyendo eventualmente a visitantes internacionales.

- Jerarquía 0, que corresponde a aquellos atractivos de mérito menor que permiten completar adecuadamente programas o itinerarios de visita.

Al respecto, dos precisiones. La primera es la aplicabilidad para esta clasificación del principio universal de «quien puede lo más puede lo menos». La segunda es que varios países, entre ellos el Perú, han optado por modificar la denominación numérica de la escala de 4 a 1, con la idea -ciertamente razonable- de que asignar el cero a una jerarquía determinada es una suerte de antivalor, en el que no vale la pena incurrir.

Muchos autores han objetado posteriormente esta jerarquización, no por considerarla inválida sino por entender que es necesario incorporar elementos más allá de la demanda. No obstante, hasta hoy, la propuesta de CICATUR continúa siendo la base de la asignación de importancia a los diversos atractivos turísticos porque justamente la demanda es el elemento determinante de la existencia del turismo.

En el Perú, en 2007, el Ministerio de Comercio Exterior y Turismo (MINCETUR), elaboró y publicó el Manual para la Formulación del Inventario de Recursos Turísticos a Nivel Nacional (http://www.mincetur.gob.pe/ turismo/Producto_turistico/Manual_de_Inventario_OCT2006_FASEII.pdf). En este documento, en nuestra opinión, se incurre en al menos dos errores fundamentales. El primero (página 6) es la consideración de dos tipos de recursos (en operación y en no operación), de modo que se puede asignar jerarquía a recursos que no son materia de demanda inicial. No hay manera de que ello no conduzca a una valoración subjetiva, dado que al no existir data de demanda, no es posible establecer conclusiones (y menos valoraciones) adecuada, siendo que la demanda es el criterio central de CICATUR. El segundo (página 9 y siguientes), es la construcción de un conjunto de criterios y ponderaciones, donde la demanda real es solo uno (en total son ocho), lo que hace que se desnaturalice el sentido de la jerarquización propuesta por CICATUR y se incluya elementos ajenos a su formulación. Esto, al menos, debería ser materia de consulta con la fuente, dado que se utiliza su estructura. Sin embargo, deberá ser el propio MINCETUR quien revise su herramienta con el propósito de reducir al mínimo sus componentes subjetivos y de asociarla mucho más a la lógica de CICATUR. Muchas veces el afán de creatividad resulta contradictorio al propósito. Este pareciera ser el caso con el Manual del

MINCETUR.

Obviamente nuestra propuesta es retornar a la lógica de CICATUR y hacer uso del criterio de demanda real para la jerarquización de los atractivos. Ello no obsta que se construya otra (u otras) herramientas para valorar recursos que aún no se encuentran colocados en el mercado turístico, pero ese es un tema diferente que podría dar lugar a algún otro artículo. Igualmente, no debería haber inconveniente para intentar incluir 
otros factores de jerarquización distintos de la demanda real, sin embargo, su uso debería alcanzar un cierto grado de consenso previo.

\section{Identificación y análisis de los mercados emisores}

Afortunadamente, el Perú dispone de importante información sobre mercados emisores como destino global. A pesar de ello, esta información existe escasamente, cuando existe, a nivel de destinos específicos y tampoco a nivel de demanda de productos especializados. Y esta escasez es la que se debe enfrentar a corto plazo si se quiere hablar de gestión de destinos turísticos.

Un destino que solo cuente con su inventario jerarquizado de atractivos, por bueno que sea, pero que no tenga idea sobre los mercados emisores que lo pueden alimentar, será siempre un destino precario.

Cada destino debe ser capaz de reconocer perfectamente a sus emisores. Para ello necesita entender a dos tipos de mercados, el mercado de interés diverso y el mercado de interés especial. El mercado de interés diverso, constituido por la gran mayoría de los turistas, organiza su visita para disfrutar distintas experiencias a lo largo de un período de permanencia, que se puede y se debe establecer claramente. Por tanto está formado por visitantes plenamente territoriales que demandan una secuencia de encuentros con la historia, la naturaleza, la gastronomía, la diversión y la modernidad. Ese es un tipo de turista, el cuantitativamente más importante para los que hay que organizar programas sumamente atractivos y variados, según los precios que estén dispuestos a pagar. El mercado de interés especial es completamente diferente porque responde a una motivación principal específica. Trátese del observador de naturaleza o del surfista, para poner un par de ejemplos, estamos hablando de visitantes que vienen a hacer algo en particular y a ellos hay que brindarles esa particularidad que buscan en primer lugar. Eso no quiere decir que no haya que pensar en otros escenarios de actividad, pero todos resultan complementarios y asociados a su interés principal. Este turista es minoritario pero permanece más tiempo y gasta más. Desde el punto de vista del movimiento económico, en el Perú, el gasto un turista de interés especial es una y media veces mayor que el gasto de un turista de interés diverso.

La gestión eficiente de un destino no solo requiere, más bien exige el conocimiento más detallado posible de los mercados emisores, sí se puede al punto de la ubicación física y del análisis de las necesidades, aspiraciones e intereses de los potenciales visitantes, a nivel de segmentos y nichos.

La investigación de mercado (cualitativa y cuantitativa) deviene imprescindible para gestionar un destino con criterio de competitividad y sostenibilidad. El mercado es un blanco (no en vano se llama target en inglés) y para dar en el blanco debemos tener el mayor conocimiento del mercado.

El análisis de mercado con base en información secundaria cuesta; el análisis de mercado con base en información primaria (estudio de mercado) cuesta más. Pero no importa cuánto cueste, hay que hacerlo. No hacerlo es lanzar el dardo con los ojos vendados y de espaldas, sin saber la distancia, ni el peso del proyectil, ni la ubicación del blanco. De repente nos resulta pero es altamente probable que no. 


\section{Mapa de actores clave}

Otro elemento informativo crucial para la construcción de un sistema integrado de gestión del destino es la identificación y ubicación de los actores clave del destino. Para el efecto debe desarrollarse el mapa de actores correspondiente. Nuevamente la identificación debe ser más bien intensiva que extensiva. De lo que se trata es de asegurar la concurrencia de los actores determinantes a la estructura de gestión del destino.

Lo primero, es hacer identificación concéntrica de los actores y privilegiar aquellos que se ubiquen en los dos primeros círculos internos. No es un error hacer un mapeo más amplio pero sí lo sería no hacer priorización.

Sin embargo, la sola identificación en completamente insuficiente. Es totalmente normal que exista disputa a priori del liderazgo entre el sector público y el sector privado, a la que muchas veces se agrega la propia sociedad civil, entendida como la organización social autónoma más que como el conjunto de ONG y asociaciones civiles del territorio.

Por tanto, se requiere ir más allá. Nos parece importante señalar algunos elementos fundamentales a considerar. Por ejemplo, la determinación de los mandatos normativos, sean legales o estatutarios o de cualquier otra índole, incluso informal como en el caso de la organización ancestral en determinadas poblaciones. Luego, la determinación de las funciones nominales y reales de cada actor.

Producida esa identificación, deberá producirse otra derivada que es la identificación de superposiciones y complementariedades. La determinación de superposiciones es muy importante porque puestas a la luz se podrá evitar conflictos innecesarios y más bien proponer alternativas de solución o de elusión de los conflictos. La determinación de complementariedades es aún más importante porque permitirá hacer uso racional y óptimo de los recursos disponibles y facilitará la identificación de rutas para morigerar las superposiciones.

En un escenario de recursos escasos la optimización de su uso es sustantiva. Si las asignaciones presupuestales del sector público -en sus tres niveles- al turismo, giran en el Perú por debajo del 0.5\%, si los actores privados son en principio renuentes a aportar a instancias de gestión colectiva en las que no confían y si las organizaciones de cooperación disponen sus recursos para el turismo según sus propios criterios, muchas veces inexpertos, podemos imaginar cuán grave es el tema de los recursos limitados para construir una estructura de gestión de destino. Lograr que públicos, privados y organismos de desarrollo concilien puntos de vista e intereses y que esto se traduzca en disposición de recursos hacia objetivos viables, es probablemente el núcleo del éxito de la gestión de un destino.

Desde este punto de vista, identificar la proactividad y vocación colaborativa de los actores es también parte del mapeo de actores, que no debe limitarse a lo descriptivo-funcional sino ampliarse a los roles institucionales concretos y cotidianos y al perfil de sus respectivos dirigentes, a fin de saber si es o no posible contar con un escenario de dinámica institucional positiva para la gestión eficiente del destino.

Más todavía, el mapeo de actores debe alcanzar al potencial operativo de los actores clave, de modo que no solo se identifique su vocación o su actitud institucional. Además de ello, debe también identificarse las ventajas operacionales que cada actor puede aportar a la estructura de gestión del destino. 
En síntesis, el mapa de actores clave de un destino turístico debe contener implícitamente todos los elementos de viabilidad de la estructura de gestión que se pueda constituir.

\section{Resultados}

Lo anteriormente mencionado ha sido probado en algunos proyectos o como parte de iniciativas, logrando resultados satisfactorios. Si bien algunos aspectos han debido ser reforzados o enfocados de distintas formas, según las realidades culturales del país y en función al apoyo que se haya podido obtener por parte de los actores involucrados en el proceso, se ha logrado una adecuada gestión de ciertos destinos locales, potenciando su desarrollo desde un mercado incipiente a un mercado mucho mayor, logrando pasar de un recurso turístico a un atractivo turístico adecuadamente manejado en beneficio de la población local.

\section{Conclusiones}

Existen aún muchos aspectos por mejorar en cuanto al desarrollo de destinos turísticos y su adecuada gestión, inclusive habiendo probado distintos modelos de gestión turística con buenos resultados no se tiene la última palabra. La interacción de todos los actores relevantes siempre es un aspecto clave para el éxito de la gestión de un destino, en especial si este es nuevo y se espera un adecuado desarrollo del mismo. Pero, para ello se debe de contar con información adecuada, actualizada y debidamente analizada. Sin la información clave y el trabajo conjunto de los actores involucrados -y con ello me refiero a que estén realmente involucrados- por más esfuerzos que se hagan no se estaría llegando a un óptimo resultado y se estaría malgastando tiempo, dinero y la oportunidad de desarrollar un destino en el momento óptimo; cuenta también las «ganas» de los actores y sobre todo de la población local de utilizar el turismo como parte de su desarrollo.

\section{Referencias}

Barrado, D. A. (2004). El concepto de destino turístico. Una aproximación geográfico-territorial. Estudios Turísticos UAM 160, $45-68$.

Boullón, R. C. (2006). Planificación del Espacio Turístico, Serie Trillas, IV Edición.

Ministerio de Comercio Exterior y Turismo - MINCETUR (2006). Manual para la Formulación del Inventario de Recursos Turísticos a Nivel Nacional. Recuperado de http://www.mincetur.gob.pe/turismo/Producto_turistico/Manual_de_Inventario_ OCT2006_FASEII.pdf 